of species such as Globigerinatella insueta Cushman and Stainforth, Globorotalia fohsi fohsi Cushman and Ellisor, $G$. fohsi lobata Bermudez and $G$. fohsi robusta Bolli were restricted to the tropical belt in the Miocene, with cooler water in the higher latitudes such as the North A.tlantic.

\section{Graham Jenkins}

University of Canterbury, New Zealand

\footnotetext{
1 Cifelli, R. Nature 264, 431-432 (1976).

2 Berggren, W. A. Init. Rep. Deep Sea Drilling Project $12,965-975$ (1972).

Jenkins, D. G. N. Z. J. Geol. Geophys. 8, 1088-1126

4 Jenkins, D. G. N. Z.J. Geol. Geophys. 10, 1064-1078 (1967).

5 Bolli, H. M. U.S. Nat. Mus. Bull. 215, 97-123 (1957) Blow, W. H. Proc. First Int. Conf. plank. microfossils (eds Bronniman, P. \& Renz, H. H.) 1, 199-422 (1969).

Jenkins, D. G. Micropaleontology (in the press)
}

8 Jenkins, D. G. Micropaleontology 11, 265-277 (1965)

Cifelli RePlies-Clearly, the proposal that warm gyral water was greatly expanded in the North Atlantic during the Miocene needs further testing against the evidence of the fossil record. But in dismissing this generalisation as idle speculation, Jenkins seems to have lost sight of my arguments and has shown nothing incompatible with 'detailed biostratigraphy'. DSDP Sites 116, 117 were interpreted oceanographically as gyral margin, not tropics and there is no reason to expect an identity in composition of faunal zones. Plankton assemblages of North Atlantic gyral margins are characterised by mixed associations of cool high latitude and sub tropical species plus lesser numbers of tropical expatriates displaced to the north by the clockwise movement of the circulation $^{1}$. Mixed associations of this kind are well represented in DSDP Sites 116,117 , as discussed in my paper. If zonation of DSDP Sites 116, 117 reminds Jenkins of New Zealand zonation, then the oceanographic significance of the latter deserves reconsideration. That is, if faunal associations are mixed, as in DSDP Sites 116, 117 margins of warm gyral water may also be represented in the New Zealand Miocene.

Jenkins points out that a bore hole of Lower Miocene age near the Isles of Scilly lacks some 'warm water' species found in Trinidad. The species, however, that he lists are all extinct ones and the nature of the habitat they occupied is unknown. Actually, those species are either the same as, or closely related to, Oligocene species which are more analogous morphotypically to modern cold water than warm water forms ${ }^{2}$. They are a bad choice for warm water indicators.

Jenkins' claim that certain species, notably the Globorotalia fohsi group is restricted to the tropical belt is nullified by Bartlett ${ }^{3}$ who recorded that species group and other tropical or subtropical forms from Nova Scotia.

\section{National Museum of Natural History, \\ Washington, DC 20560 \\ R. Cifelli \\ 1 Cifelli, R. \& Benier, C. J. Foram. Res. 6, 259 (1976) \\ 2 Cifelli, R. Syst. Zool. 18, 154 (1969).}

U-shaped gene frequency distributions

Gilpin et al. ${ }^{1}$ have recently questioned the usefulness of the frequency distribution of allele frequencies as a means of distinguishing between the neoclassical (neutralist) and balance (selectionist) interpretations of genic variation in natural populations. The conventional view has been that random genetic drift will generate a U-shaped distribution of allele frequencies at equilibrium, while all allele frequencies will be equally probable if they represent stable equilibria maintained by the superiority of heterozygotes. Gilpin et al. argue that the assumption of equiprobability is gratuitous, and that the frequency distribution of allele frequencies amongst overdominant loci will be determined by the joint probability distribution of the selection coefficients acting on the homozygotes. In particular, U-shaped frequency distributions are to be expected if the probability of obtaining a given selection coefficient falls off steeply with the magnitude of the coefficient. Such a distribution of selection coefficients seems plausible, and is in any case similar to that which is claimed to be the case by the neutralist school.

The result obtained by Gilpin et al. applies to overdominant loci, treated deterministically. It may be worth pointing out that a U-shaped equilibrium distribution of allele frequencies will also be generated deterministically amongst loci at which the heterozygote is intermediate in fitness. Consider a locus with two alleles, $A I$ and $A 2$, whose frequencies are $p$ and $q$ respectively. If the selection coefficient and the degree of dominance are given, the rate of substitution will vary directly with the genic variance, $p q$. Since this is maximal at $p=q=\frac{1}{2}$, and is minimal when either allele is near fixation, substitution will proceed rapidly at intermediate allele frequencies, but very slowly when either allele is very common. If we imagine an ensemble of loci behaving in this way, it is easy to see that most loci will accumulate in the regions where the rate of movement of allele frequency is lowest, that is near $p=1$ and near $p=0$. In this way, the frequency distribution of allele frequencies at loci which are undergoing directional selec- tion in an infinite population will be U-shaped at equilibrium.

Department of Biology,

McGill University,

Montreal, Quebec, Canada H3A IBI

${ }^{1}$ Gilpin, E. A. et al. Nature 263, 497-499 (1976).

ONDRICEK et al. REPLY-Bell correctly notes a possibility we had not considered, namely that the commonly observed U-shaped allele frequency distribution is to be expected assuming that polymorphic loci are in the process of becoming fixed for a better allele; this is simply because the fastest rate for change of transient polymorphisms is at intermediate gene frequencies.

Two predictions follow from his model. The first is that the rate of evolution of a population is proportional to its level of heterozygosity. There are insufficient data to test this, but the common finding of high heterozygosities in physically stable environments (the deep sea $a^{2,3}$ and the tropics $^{4,5}$ ) is not auspicious. Nor is the occurrence of moderate levels of variation in a 'living fossil', Limulus polyphemus $^{6}$, consistient with such a theory.

Second, the transient polymorphism model would predict that frequencies in the middle range, say 0.7 to 0.3 , should not be conserved; that is, if related species or isolated populations of the same species share polymorphisms with allele frequencies in this range, it would argue for balancing selection. Tenacity for intermediate allele frequencies seems to be rather common. For example, the Lacerta data ${ }^{7}$ show that $L$. melisellensis retains two alleles at intermediate frequencies for phosphoglucomutase- 2 on all islands larger than $0.05 \mathrm{~km}^{2}$, and $L$. sicula shows the same pattern for esterase- 4 . Among four species of the willistoni group of Drosophila, the analogous pattern is observable for aldolase, xanthine dehydrogenase, and adenylate kinase-2 (ref. 4). The examples could be multiplied.

In summary, we think it likely that only a small fraction of polymorphic loci are transient, and in the process of becoming fixed for an overall 'better' allele.

Anatola OndriceK

E. A. Gilpin
M. E. Soule
M. E. Gilpin

Biology Department

University of California, San Diego

La Jolla, California 92037

1 Bell, G. Nature 268, 374 (1977).

2 Schoof, T. J. M. \& Gooch, G. L. J. Geol. 80, 481-483

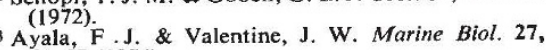
$51-57(1974)$

4 Ayala, F. \& Tracy, M. L. Proc. natn. Acad. Sci.

5 Somero, G. N. \& Soule, M. Nature 249, 670-672 (1974)

Selander, R. K., Yang, S. Y., Lewontin, R. C. \& Gonson, $C$. Soulé $M$ Yang, S. Y \& Nevo, E, Evolution 29, 52-71 (1975). 